\title{
Study on Effects of Electrical Stimulation on Rabbit Esophageal Body Motility In Vivo
}

\author{
Lili ZHANG ${ }^{1}$, Wei ZHAO ${ }^{1}$, Chunshan $\mathrm{ZHAO}^{1}$, Hong $\mathrm{JIN}^{1}$, Bin WANG ${ }^{1}$, Bangmao WANG ${ }^{1}$ \\ ${ }^{1}$ Department of Digestive Diseases, General Hospital, Tianjin Medical University, Tianjin, China
}

Received April 14, 2017

Accepted October 9, 2017

On-line January 5, 2018

\section{Summary}

Electric stimulation (ES) could induce contraction of intestinal smooth muscle. The aim of this study was to analyze the effects of ES on esophageal motility and the underlying mechanism in vivo. Twenty-eight rabbits were equipped with a pair of subserosa electrodes (connected to an electrical stimulator) in the lower segment of the esophagus. The ES signal consisted of bipolar rectangular pulse trains, lasting for $3 \mathrm{~s}$, with different amplitudes (1 mA, $3 \mathrm{~mA}, 5 \mathrm{~mA}$ and $10 \mathrm{~mA})$, and frequencies $(10 \mathrm{~Hz}, 20 \mathrm{~Hz}$ and $50 \mathrm{~Hz}$ ). The amplitude of the contraction was recognized by high-resolution manometry. The effect of ES was tested under anesthesia and following administration of atropine, phentolamine or L-NAME. ES induced esophageal contraction at the stimulated site. A statistically significant increase in esophageal pressure was observed when the stimulation amplitude was above $3 \mathrm{~mA}$. The increase in esophageal pressure was associated with the amplitude of stimulus as well as the frequency. During stimulation, atropine, phentolamine and L-NAME had no effect on the increase of esophageal pressure induced by ES. These findings implied that ES induced esophageal contraction were not mediated via the NANC, adrenergic or cholinergic pathway. The amplitude of esophageal contraction was current and frequency dependent.

\section{Key words}

Electrical stimulation - Esophagus motility - High-resolution manometry

\section{Corresponding authors}

B. Wang and W. Zhao, Department of Digestive Diseases, General Hospital, Tianjin Medical University, Tianjin 300052, China. Fax: +86 02260362608. E-mail: tjmughgi@hotmail.com

\section{Introduction}

Achalasia may be defined as a primary esophageal motility disorder, characterized by aperistalsis of the esophageal body and incomplete relaxation of the lower esophageal sphincter (LES). Current treatment options for achalasia include pharmacological agents, pneumatic dilation, surgical myotomy and high-resolution manometry peroral endoscopic myotomy. All these methods are intended to decrease the pressure of LES by relaxing the LES, but they cannot improve esophageal motility, especially the recovery of peristalsis. Many patients still suffer from dysphagia after one or two types of therapy because of abnormal esophageal motility, so there is an urgent need for new treatment modalities that improve esophageal motility and restore esophageal peristalsis.

Recently, there has been increased interest in electrical stimulation (ES) to regulate gut motility. Gastric electrical stimulation and intestinal electrical stimulation can increase gastric emptying and intestinal transit, respectively (Song and Chen 2011, Yin and Chen 2007, Mintchev et al. 2000). Gastric electrical stimulation has been used to treat gastroparesis and morbid obesity in clinical practice (Jayanthi et al. 2013, Xu et al. 2005, Guerci et al. 2012). Experiments have confirmed that colonic electrical stimulation with pulse trains has prokinetic effects on colonic contractions and transit, which provide a hope for treatment of constipation with ES (Liu and Chen 2006, Amaris et al. 2002, Aellen et al. 2009, Martellucci and Valeri 2014). In recent years, more research has indicated that esophageal ES could increase the pressure of LES and provide a good therapeutic effect 
on gastroesophageal reflux disease (Banerjee et al. 2014, Rodriguez et al. 2013). However, little study has reported whether esophageal ES can regulate esophageal motility and treat esophageal motility disorders, such as achalasia.

We hypothesized that ES delivered locally to the esophageal body in vivo would evoke esophageal body contraction and then regulate esophageal motility. Therefore, the aim of this study was to investigate the effects of ES on esophageal motility in a rabbit model and explore the mechanism of this action. We chose stimulus parameters proven to change esophageal pressure or generate smooth muscle contraction in our preliminary experiment.

\section{Materials and Methods}

\section{Animal preparation}

Twenty-eight adult male New Zealand white rabbits (1.0-2.0 kg, Institute of animal research, Nanjing University, China) were included in this study. After an overnight fast, each animal underwent surgery under general anesthesia (1.5\% iso-flurane inhalation). A midline laparotomy was performed and the lower segment of the esophagus was exposed. One pair of custom-designed stainless steel wire electrodes $(5 \times 1 \mathrm{~mm})$ were implanted at the subserosa of the lower segment of the esophagus ( $2 \mathrm{~cm}$ above the LES). The two electrodes in the circumferential pair (one active and one ground) were oriented longitudinally and positioned diametrically opposite on the esophageal surface. The electrodes were connected to a multi-channel signal stimulator (A.M.P.I., Israel) by stainless steel wires. The study was approved by the Animal Care and Use Committee of the General Hospital, Tianjin Medical University, Tianjin, China.

\section{Esophageal manometry}

For the esophageal motility study, esophageal manometry was performed by water-perfusion highresolution manometry (HRM) with a 22-channel catheter (Medical Measurement Systems, Enschede, the Netherlands) after implantation of electrodes. The esophageal manometry catheter was placed through the mouth of the rabbit into the esophagus and was positioned with the 5 dense sensors straddling the lower segment of the esophagus and the other 17 openings of the catheter located in the esophageal body. Continuous recordings of the pressure of the segment located with electrodes and of esophageal motility were obtained before, after and during each stimulation period.

\section{ES of the lower segment of esophagus}

This part of the experiment, performed with 12 rabbits, aimed to assess the effect of ES on esophageal body pressure and esophageal motility. The esophageal ES was controlled by a multi-channel signal stimulator delivering bipolar rectangular pulse trains (output current range $\pm 10 \mathrm{~mA}$, output current limit $10 \mathrm{~mA}$ ). According to our preliminary experiments, some stimulation parameters considered optimal for rabbit esophageal smooth muscle were selected: $1 \mathrm{~mA}, 3 \mathrm{~mA}, 5 \mathrm{~mA}$ and $10 \mathrm{~mA}$ current and $10 \mathrm{~Hz}, 20 \mathrm{~Hz}$ and $50 \mathrm{~Hz}$ frequency. To investigate the reaction of the esophageal body to $\mathrm{ES}$ and determine the optimal current and frequency to influence esophageal motility, we applied the above currents and frequencies randomly as stimulation parameters. Pulse duration equal to the interval of two pulses was used, according to the frequency. Each rabbit underwent 12 stimulation sessions based on the above stimulation parameters. During each session, a different set of stimulation parameters was used, as described in Table 1. Each type of stimulation was given randomly and delivered as monophasic pulses. Trains of pulses were delivered for a few seconds every minute (Table 1) for the duration of the stimulation period. Each session lasted $10 \mathrm{~min}$. Tissue impedance between the electrodes was checked at the beginning of each session to ensure that the electrodes were still anchored in the esophageal body muscle. Changes of esophageal pressure and motility induced by ES, as well as the latency period between ES and the contraction of the esophagus, were recorded by HRM synchronously.

\section{Neuromechanism of ES}

This part of the experiment, performed with the other 16 rabbits, was designed to explore the mechanisms by which ES has its effects. Continuous esophageal manometry recordings were obtained during $30 \mathrm{~min}$ of ES on the lower segment of the esophagus with the parameters of sessions 7,8 , and 9 , as described in Table 1. Thirty milliliters of $0.9 \%$ saline was intravenously injected before $\mathrm{ES}$ as a control. The experiment to investigate the role of adrenergic, cholinergic and non-adrenergic and non-cholinergic (NANC) neurons in mediating the effects of ES on the esophageal body was performed after the above stimulation protocols were completed. 
Table 1. Types of stimulation.

\begin{tabular}{lccccc}
\hline ES type & $\begin{array}{c}\text { Pulse frequency } \\
(\mathbf{H z})\end{array}$ & $\begin{array}{c}\text { Train duration } \\
(\mathbf{s})\end{array}$ & $\begin{array}{c}\text { Pulse duration } \\
(\mathbf{m s})\end{array}$ & $\begin{array}{c}\text { Pulse amplitude } \\
(\mathbf{m A})\end{array}$ & Trains/min \\
\hline Session 1 & 10 & 3 & 100 & 1 & 1 \\
Session 2 & 20 & 3 & 50 & 1 & 1 \\
Session 3 & 50 & 3 & 20 & 1 & 1 \\
Session 4 & 10 & 3 & 100 & 3 & 1 \\
Session 5 & 20 & 3 & 50 & 3 & 1 \\
Session 6 & 50 & 3 & 20 & 3 & 1 \\
Session 7 & 10 & 3 & 100 & 5 & 1 \\
Session 8 & 20 & 3 & 50 & 5 & 1 \\
Session 9 & 50 & 3 & 20 & 5 & 1 \\
Session 10 & 10 & 3 & 100 & 10 & 1 \\
Session 11 & 20 & 3 & 50 & 10 & 1 \\
Session 12 & 50 & 3 & 20 & 10 & 1 \\
\hline
\end{tabular}

This table depicts the parameters used in each type of electrical stimulation (ES) applied to the lower segment of rabbits esophagus $(n=12)$. Each type of stimulation was applied at random and for $10 \mathrm{~min}$.

To explore whether the effects of ES on the esophageal pressure were mediated by NANC nerves, the inhibitor of the main neurotransmitter of NANC nerves was utilized. After a pause of $10 \mathrm{~min}, \mathrm{~L}-\mathrm{N}^{\mathrm{G}}$-nitro arginine (L-NNA, Sigma Aldrich, St. Louis, MO, USA) was administered i.v. to 4 rabbits over a few minutes to reach a total dose of $50 \mathrm{mg} / \mathrm{kg}$. L-NNA is an inhibitor of NO synthase that inhibits endogenous production of NO. Twenty to thirty minutes after the medication was administered, ES was delivered again for 30 min with the above parameters.

To explore whether the cholinergic pathway was involved in the effect of ES on esophageal pressure, atropine, the inhibitor of cholinergic nerves, was utilized. After a pause of $10 \mathrm{~min}$, atropine $(0.05 \mathrm{mg} / \mathrm{kg}$, Gensia Sicor Pharmaceuticals, Irvine, CA, USA) was administered to other 4 rabbits as an i.v. bolus and 2 min later ES was delivered for $30 \mathrm{~min}$ with the same parameters as above.

To explore whether the effects of ES on esophageal pressure were mediated by the adrenergic pathway, the inhibitor of adrenergic nerves phentolamine was utilized. After a pause of $10 \mathrm{~min}$, phentolamine (Sigma Aldrich, St. Louis, MO, USA) was administered by intravenous injection to the last 4 rabbits over a few minutes to reach a total dose of $1 \mathrm{mg} / \mathrm{kg}$, and 2 min later ES was delivered for $30 \mathrm{~min}$ with the same parameters as above. All rabbits underwent euthanasia at the end of the experiment with air injection.

\section{Statistical analysis}

The SPSS 18.0 software package was used for statistical data analyses (SSPS, Inc., Chicago, IL, USA). For each type of stimulation, the mean pressure in a segment of the esophagus was determined over $10 \mathrm{~min}$ for each of the following periods: 1) baseline; 2) stimulation; and 3) poststimulation. The latency period between ES and esophageal contraction and the scope of esophageal contraction were also calculated by averaging the 10-min recording of each type of stimulation. An ANOVA for repeated measures was used to assess differences between periods and types of stimulation. A Spearman correlation was applied for correlation analysis between stimulation amplitude and esophageal pressure, as well as stimulation frequency and esophageal pressure.

For the second experiment, the pressure of the lower segment of the esophagus was measured for the entire ES duration in each period. Changes in the mean esophageal pressure with the same stimulation parameters before and after utilization of the drug (L-NNA, atropine or phentolamine) were recorded in each period. ANOVA for repeated measures was used to assess differences between the changes in pressure.

Data are presented as means \pm SD. $P<0.05$ was considered statistically significant, otherwise it was nonsignificant (NS). 
Table 2. Effect of ES on the lower segment of rabbits esophagus $(n=12)$.

\begin{tabular}{|c|c|c|c|}
\hline \multirow{2}{*}{ Stimulation parameter } & \multicolumn{3}{|c|}{ Lower segment of esophageal body pressure, $\mathrm{mm} \mathrm{Hg}$} \\
\hline & Baseline & Stimulation & Poststimulation \\
\hline $1 \mathrm{~mA}, 10 \mathrm{~Hz}$ & $16.2 \pm 2.4$ & $16.3 \pm 3.1$ & $16.2 \pm 4.5$ \\
\hline $1 \mathrm{~mA}, 20 \mathrm{~Hz}$ & $16.1 \pm 2.8$ & $15.9 \pm 3.7$ & $16.1 \pm 3.8$ \\
\hline $1 \mathrm{~mA}, 50 \mathrm{~Hz}$ & $16.0 \pm 3.4$ & $16.1 \pm 2.6$ & $16.1 \pm 2.9$ \\
\hline $3 \mathrm{~mA}, 10 \mathrm{~Hz}$ & $16.2 \pm 1.7$ & $39.5 \pm 1.8^{*}$ & $16.2 \pm 3.5$ \\
\hline $3 \mathrm{~mA}, 20 \mathrm{~Hz}$ & $16.2 \pm 3.7$ & $46.2 \pm 5.3^{*}$ & $16.2 \pm 5.1$ \\
\hline $3 \mathrm{~mA}, 50 \mathrm{~Hz}$ & $16.1 \pm 4.5$ & $67.0 \pm 5.3 *$ & $16.0 \pm 4.1$ \\
\hline $5 \mathrm{~mA}, 10 \mathrm{~Hz}$ & $15.9 \pm 4.6$ & $72.2 \pm 4.6^{*}$ & $15.8 \pm 5.3$ \\
\hline $5 \mathrm{~mA}, 20 \mathrm{~Hz}$ & $15.9 \pm 3.6$ & $101.2 \pm 5.7 *$ & $15.8 \pm 4.7$ \\
\hline $5 \mathrm{~mA}, 50 \mathrm{~Hz}$ & $16.2 \pm 4.2$ & $110.2 \pm 2.7 *$ & $16.2 \pm 3.9$ \\
\hline $10 \mathrm{~mA}, 10 \mathrm{~Hz}$ & $16.2 \pm 5.5$ & $131.8 \pm 3.5^{*}$ & $16.1 \pm 4.2$ \\
\hline $10 \mathrm{~mA}, 20 \mathrm{~Hz}$ & $16.0 \pm 4.1$ & $141.3 \pm 3.7 *$ & $16.1 \pm 5.2$ \\
\hline $10 \mathrm{~mA}, 50 \mathrm{~Hz}$ & $16.1 \pm 3.4$ & $155.6 \pm 3.6^{*}$ & $16.1 \pm 4.5$ \\
\hline
\end{tabular}

$* P<0.01$ vs. control.

\section{Results}

Effect of esophageal ES on the lower segment of the esophagus

Esophageal manometry was well tolerated by all animals $(n=12)$. As shown in Table 2, a statistically significant increase in lower segment pressure was observed when the stimulation amplitude was $3 \mathrm{~mA}$. The esophageal pressure was $16.2 \pm 1.7 \mathrm{~mm} \mathrm{Hg}$ at baseline and increased by $143 \%$ to $39.5 \pm 1.8 \mathrm{~mm} \mathrm{Hg}$ during esophageal ES $(P<0.01$ vs. baseline) with parameters of $3 \mathrm{~mA}, 10 \mathrm{~Hz}, 50 \mathrm{~ms}$, and then immediately recovered to the baseline level after the cessation of ES. Similar to these conditions, the esophageal body pressure increased to $72.2 \pm 4.6 \mathrm{~mm} \mathrm{Hg}$ with stimulation of $5 \mathrm{~mA}, 10 \mathrm{~Hz}$, and to $131.8 \pm 3.5 \mathrm{~mm} \mathrm{Hg}$ with stimulation of $10 \mathrm{~mA}, 10 \mathrm{~Hz}$ $(P<0.01)$ (Table 2). The baseline pressure was consistent and stable in the twelve different sessions on different rabbits (NS). Compared with baseline, pressure during poststimulation was not significantly increased in any session (NS), which indicated that the esophageal body relaxed soon after the end of ES. The increase in esophageal pressure was associated with the amplitude of the stimulus as well as the frequency of the stimulus. A higher increase in esophageal pressure was noted with a higher stimulation amplitude (Fig. 1A) or a higher stimulation frequency (Fig. 1B). The esophageal pressure during stimulation was found to be positively correlated with the stimulation amplitude $(\mathrm{r}=0.970 ; P<0.001)$ and stimulation frequency $(\mathrm{r}=0.942, P<0.001$; Fig. 2$)$. In addition, the latency period between stimulation and esophageal contraction was $53.9 \pm 5.2 \mathrm{~ms}$, which was not significantly different among the above stimulation parameters (Fig. 3). Analogously, the contraction scope was not obviously changed among different stimulation parameters and was restricted to the stimulation point (NS).

Effects of ES on esophageal body pressure in presence of L-NNA, atropine and phentolamine

The effect of ES on the rabbits esophageal body pressure was not mediated via the NANC, adrenergic or cholinergic pathway $(n=16)$. Atropine did not block the effect of esophageal ES on the esophageal body pressure; in the presence of atropine, ES still significantly increased the esophageal pressure, and the increase was comparable to that in the control session with saline (Fig. 4). Phentolamine and L-NNA did not block the effect of ES on the esophageal body pressure. As Figure 2 shows, the esophageal body pressure during stimulation was increased significantly with blockage of phentolamine or L-NNA, and the increase was not obviously different from that in the control session with saline. 
A

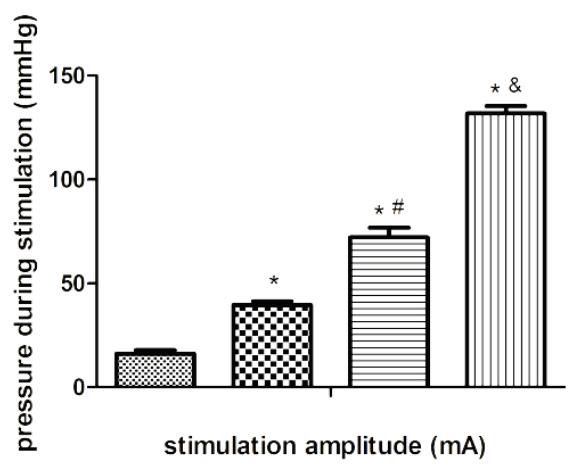

B

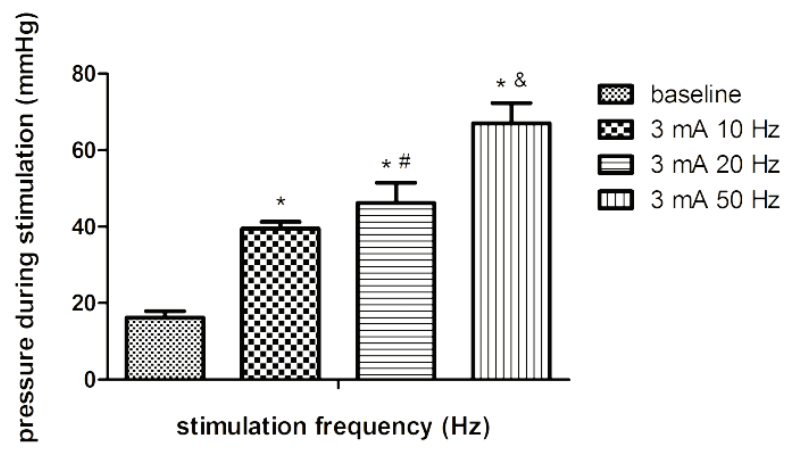

Fig. 1. The esophageal body pressure during baseline and stimulation with different parameters $(n=12)$. A. Esophageal pressure during ES with different stimulation amplitudes ( $3 \mathrm{~mA}, 5 \mathrm{~mA}$ and $10 \mathrm{~mA})$ at a frequency $(10 \mathrm{~Hz})$ and a pulse $(50 \mathrm{~ms}) . * P<0.01 \mathrm{vs}$. baseline; $\# P<0.05$ vs. $3 \mathrm{~mA} ; \& P<0.01$ vs. $3 \mathrm{~mA}$ or $5 \mathrm{~mA}$. B. The esophageal body pressure during ES with different stimulation frequencies $(10 \mathrm{~Hz}, 20 \mathrm{~Hz}$ and $50 \mathrm{~Hz})$ at a pulse amplitude $(3 \mathrm{~mA})$. $* P<0.05$ vs. baseline; $\# P<0.01 \mathrm{vs.} 10 \mathrm{~Hz} ; \& P<0.01 \mathrm{vs.} 10 \mathrm{~Hz}$ or $20 \mathrm{~Hz}$.
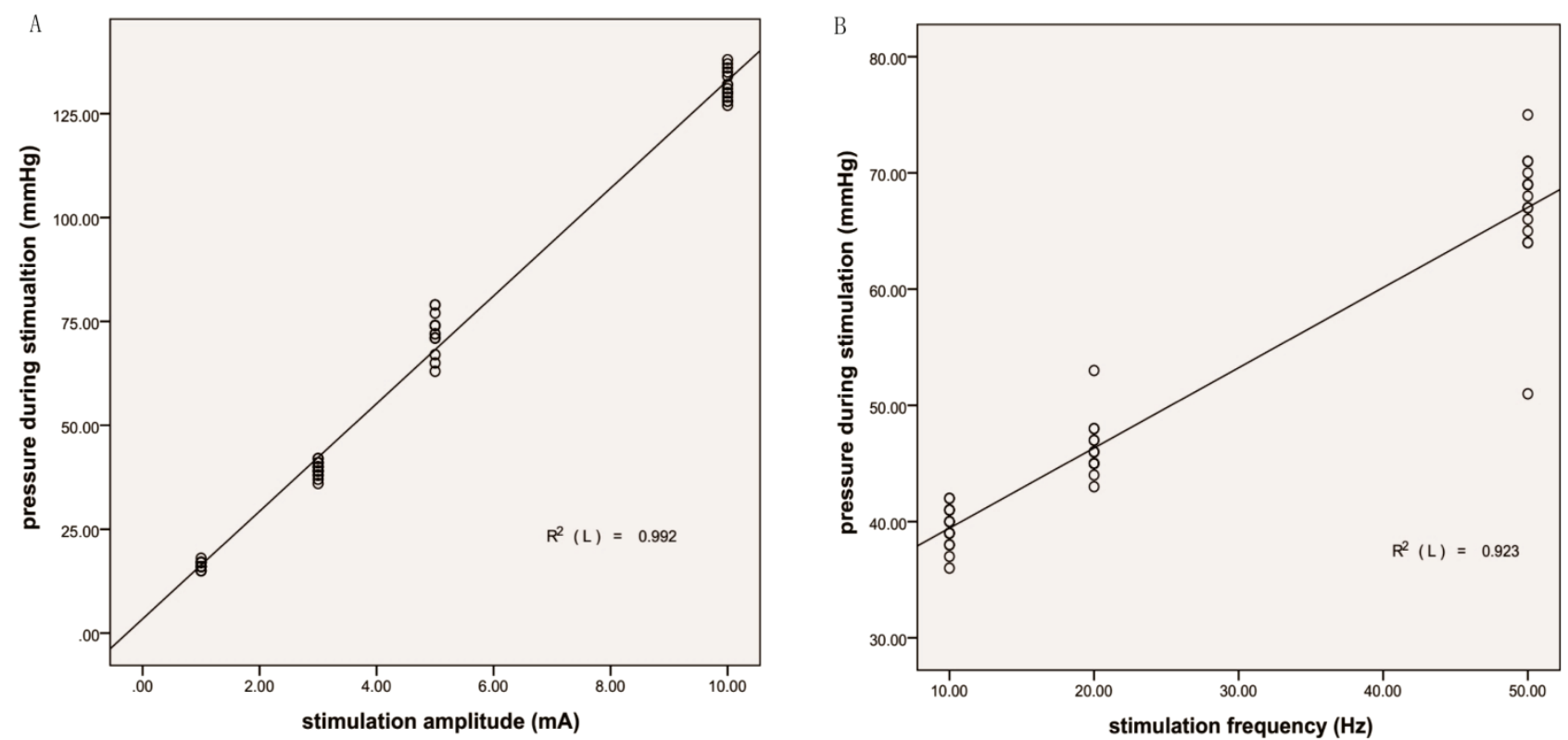

Fig. 2. Correlation between electrical stimulation parameter and pressure of stimulation segment in esophageal body. The results suggested that the esophageal pressure during stimulation was positively correlated with the stimulation amplitude $(\mathrm{r}=0.970 ; P<0.001)$ and stimulation frequency $(r=0.942, P<0.001)$.

\section{Discussion}

This study has shown that esophageal ES increased the esophageal body pressure in the healthy rabbits and that the effect was stimulation amplitude and frequency dependent. The antagonists of NANC nerves, cholinergic nerves and adrenergic nerves, L-NNA, atropine and phentolamine, respectively, all did not block the effect of ES on the esophageal body.

Although there have been many studies regarding esophageal electric stimulation, the methods used in the current study are fundamentally different from those reported in the literature (Rodriguez et al. 2013,
Sanmiguel et al. 2008, Christensen and Lund 1969). In the previous studies, ES used to treat gastroesophageal reflux disease (GERD) was delivered at $20 \mathrm{~Hz}, 3-8 \mathrm{~mA}$, $215 \mu \mathrm{s}$ in multiple 30-min sessions (Rodriguez et al. 2013). In that method, a train of short pulses with a pulse width of $215 \mu$ s and a long duration of 30 min was given repeatedly. In the current study, esophageal ES was performed using a train of pulses approximately $10-50 \mathrm{~ms}$, with a short total duration of $3 \mathrm{~s}$. That is, the width of pulses used in the current study was approximately 100 times that used in the previous study, whereas the duration of ES was $10 \%$ of that used in the previous study. The selection of different stimulation 


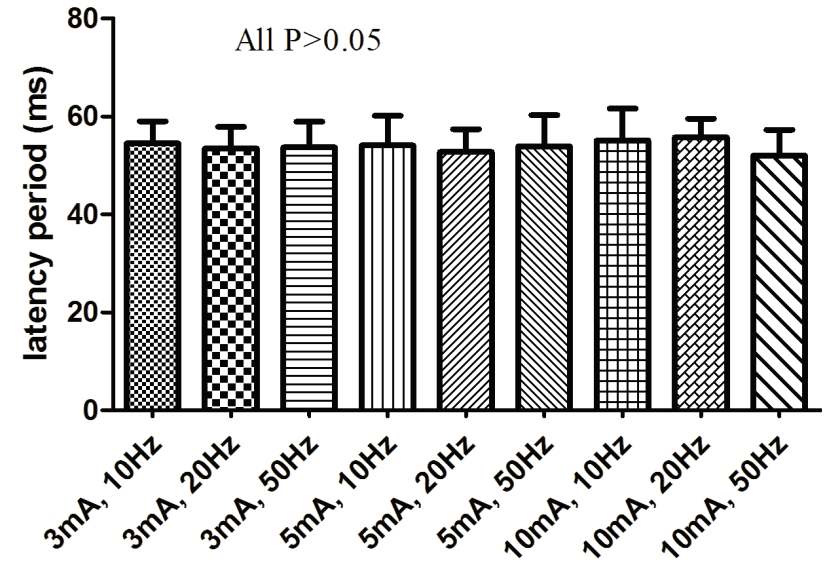

Fig. 3. The latency period between electrical stimulation with different parameters and esophageal contraction. There was no significantly different on latency period among the above stimulation parameters. All were nonsignificant ( $P>0.05)$.

parameters was based on the different aims of the two studies. The aim of the previous study was to increase LES pressure chronically to treat GERD, whereas the current study aimed to induce esophageal contraction immediately to promote esophageal peristalsis. Based on the aim and our preliminary study, the current study chose a longer pulse and a shorter duration.

The effects of ES on the gastrointestinal tract are inconsistent and even conflicting (Yang et al. 2004, Yao et al. 2005), but one consistent result in that ES increases the pressure of the stimulated segment (Nie et al. 2006, Rashev et al. 2002). Esophageal ES was always studied to stimulate the LES and then used to treat GERD, which has achieved greatly success clinically (Rodríguez et al. 2013a,b, Rodríguez et al. 2012). It has been reported that short pulses stimulation caused a sustained increase in LESP in canine model: $32.1 \pm 12.9$ (prestimulation) vs. $43.2 \pm 18.0$ (stimulation) vs. $50.1 \pm 23.8$ (poststimulation) (Sanmiguel et al. 2008). The LESP during poststimulation was still increased significantly compared to that during prestimulation. In contrast, the esophageal body pressure decreased to baseline during poststimulation in this study, and the difference between them may owe to different stimulation durations and parameters used in the train of pulses. Consistent with our study, Sallam and Chen (2013) showed that electrical stimulation with a train of pulses could induce colonic contraction and increase colonic pressure. In addition, numerous previous studies with gastric or intestinal electric stimulation have reported that electric stimulation was capable of entraining gastric or intestinal slow waves (Lin and Chen 2002, Hocking et al. 1992, Lin et al. 1998), altering gastric or intestinal contractions (Eagon
A

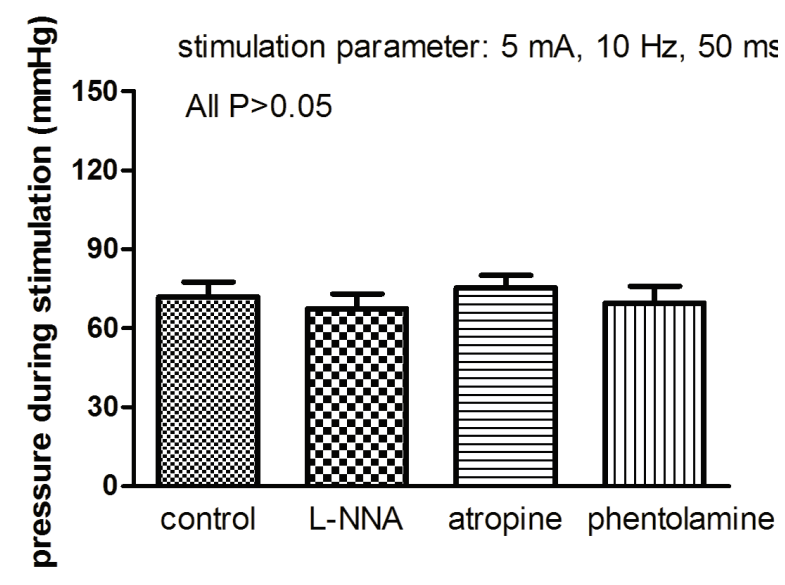

B

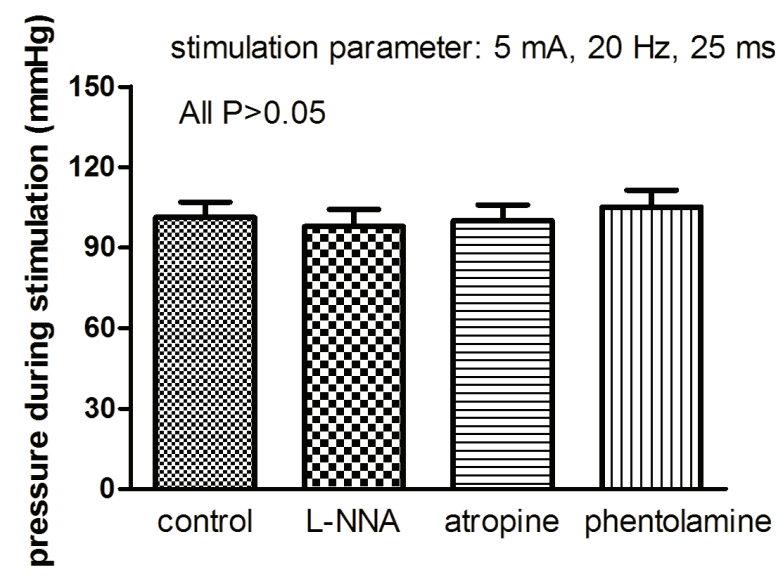

C

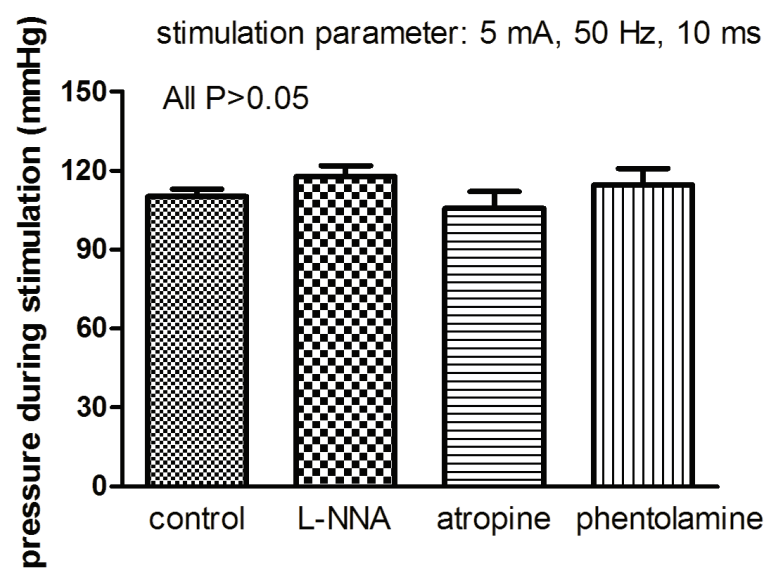

Fig. 4. Possible mechanism of esophageal ES involving NANC, cholinergic and adrenergic pathways $(n=16)$. A. Esophageal body pressure during stimulation with $5 \mathrm{~mA}, 10 \mathrm{~Hz}$ and $50 \mathrm{~ms}$ in the condition of control, L-NNA, atropine or phentolamine. All were nonsignificant $(P>0.05)$. B. Esophageal pressure during stimulation with $5 \mathrm{~mA}, 20 \mathrm{~Hz}$ and $25 \mathrm{~ms}$ in the condition of control, L-NNA, atropine or phentolamine. All were nonsignificant $(P>0.05)$. C. Esophageal pressure during stimulation with $5 \mathrm{~mA}$, $50 \mathrm{~Hz}$ and $10 \mathrm{~ms}$ at present of control, L-NNA, atropine or phentolamine. All were nonsignificant $(P>0.05)$. 
and Kelly 1995), and accelerating gastric emptying (Bellahsène et al. 1992, Lin et al. 2011, McCallum et al. 1998, Ouyang et al. 2003), which was consistent with our results as well as our ultimate goal of accelerating esophageal emptying. In our preliminary research, the threshold for inducing an increase in esophageal body pressure was found to be a stimulation frequency of $10 \mathrm{~Hz}$, a pulse width of $50 \mathrm{~ms}$, and amplitude of $3 \mathrm{~mA}$. Further experiments and analyses revealed a correlation between the increased esophageal pressure and the stimulation amplitude, frequency or stimulation energy.

Mechanisms involved in the effect of ES on the esophageal body pressure were not clarified before. In this study, we found that the prokinetic effect of esophageal ES appeared to be not mediated via the NANC, cholinergic or adrenergic pathways. It is possible that pulse-train esophageal ES acted directly on some ionic channel of esophageal smooth muscle cells to induce esophageal contraction. This would not agree with the previous study in which both cholinergic and nitrergic pathways were involved in mediating the excitatory effect of colonic ES (Sallam and Chen 2013). The reason for this discrepancy may be associated with difference in the anatomical structure and nerve distribution between the esophagus and colon. Sanmiguel et al. (2008) reported that the effect of ES on LES was mediated via cholinergic nerves. The nitrergic pathway-mediated mechanism was also previously reported (Forster et al. 2001). These findings are not consistent, and more research is needed to elucidate the mechanism of ES.

The findings of the present study suggest the therapeutic potential of esophageal ES for the esophageal dysmotility diseases. Esophageal ES induced esophageal contraction temporarily at the stimulated site in vivo, and this effect was not mediated by neurotransmitters, which made it easier to stimulate esophageal body sequentially with successive electrodes and then motivate esophageal peristalsis in the future. Further studies are warranted to explore the effects of sequentially electrical stimulation on esophageal body peristalsis and its feasibility.

\section{Conflict of Interest}

There is no conflict of interest.

\section{Acknowledgements}

The work was supported by National Natural Science Foundation of China $(81370492,81600425)$.

\section{References}

AELLEN S, WIESEL PH, GARDAZ JP, SCHLAGETER V, BERTSCHI M, VIRAG N, GIVEL JC: Electrical stimulation induces propagated colonic contractions in an experimental model. Br J Surg 96: 214-220, 2009.

AMARIS MA, RASHEV PZ, MINTCHEV MP, BOWES KL: Microprocessor controlled movement of solid colonic content using sequential neural electrical stimulation. Gut 50: 475-479, 2002.

BANERJEE R, PRATAP N, KALPALA R, REDDY DN: Effect of electrical stimulation of the lower esophageal sphincter using endoscopically implanted temporary stimulation leads in patients with reflux disease. Surg Endosc 28: 1003-1009, 2014.

BELLAHSENE BE, LIND CD, SCHIRMER BD, UPDIKE OL, MCCALLUM RW: Acceleration of gastric emptying with electrical stimulation in a canine model of gastroparesis. Am J Physiol 262: G826-G834, 1992.

CHRISTENSEN J, LUND GF: Esophageal responses to distension and electrical stimulation. J Clin Invest 48: 408-419, 1969.

EAGON JC, KELLY KA: Effect of electrical stimulation on gastric electrical activity, motility and emptying. Neurogastroenterol Motil 7: 39-45, 1995.

FORSTER J, SAROSIEK I, DELCORE R, LIN Z, RAJU GS, MCCALLUM RW: Gastric pacing is a new surgical treatment for gastroparesis. Am J Surg 182: 676-681, 2001.

GUERCI B, BOURGEOIS C, BRESLER L, SCHERRER ML, BÖHME P: Gastric electrical stimulation for the treatment of diabetic gastroparesis. Diabetes Metab 38: 393-402, 2012.

HOCKING MP, VOGEL SB, SNINSKY CA: Human gastric myoelectric activity and gastric emptying following gastric surgery and with pacing. Gastroenterology 103: 1811-1816, 1992.

JAYANTHI NV, DEXTER SP, SARELA AI: Gastric electrical stimulation for treatment of clinically severe gastroparesis. J Minim Access Surg 9: 163-167, 2013.

LIN Z, CHEN JD: Advances in gastrointestinal electrical stimulation. Crit Rev Biomed Eng 30: 419-457, 2002. 
LIN Z, SAROSIEK I, FORSTER J, ROSS RA, CHEN JD, MCCALLUM RW: Two-channel gastric pacing in patients with diabetic gastroparesis. Neurogastroenterol Motil 23: 912-e396, 2011.

LIN ZY, MCCALLUM RW, SCHIRMER BD, CHEN JD: Effects of pacing parameters on entrainment of gastric slow waves in patients with gastroparesis. Am J Physiol 274: G186-G191, 1998.

LIU S, CHEN JD: Colonic electrical stimulation regulates colonic transit via the nitrergic pathway in rats. Dig Dis Sci 51: 502-505, 2006.

MARTELLUCCI J, VALERI A: Colonic electrical stimulation for the treatment of slow-transit constipation: a preliminary pilot study. Surg Endosc 28: 691-697, 2014.

MCCALLUM RW, CHEN JD, LIN Z, SCHIRMER BD, WILLIAMS RD, ROSS RA: Gastric pacing improves emptying and symptoms in patients with gastroparesis. Gastroenterology 114: 456-461, 1998.

MINTCHEV MP, SANMIGUEL CP, AMARIS M, BOWES KL: Microprocessor-controlled movement of solid gastric content using sequential neural electrical stimulation. Gastroenterology 118: 258-263, 2000.

NIE Y, PASRICHA JP, CHEN JD: Anal electrical stimulation with long pulses increases anal sphincter pressure in conscious dogs. Dis Colon Rectum 49: 383-391, 2006.

OUYANG H, YIN J, ZHU H, XU X, CHEN JD: Effects of gastric electrical field stimulation with long pulses on gastric emptying in dogs. Neurogastroenterol Motil 15: 409-416, 2003.

RASHEV PZ, AMARIS M, BOWES KL, MINTCHEV MP: Microprocessor-controlled colonic peristalsis: dynamic parametric modeling in dogs. Dig Dis Sci 47: 1034-1048, 2002.

RODRÍGUEZ L, RODRIGUEZ P, NETO MG, AYALA JC, SABA J, BEREL D, CONKLIN J, SOFFER E: Short-term electrical stimulation of the lower esophageal sphincter increases sphincter pressure in patients with gastroesophageal reflux disease. Neurogastroenterol Motil 24: 446-450, e213, 2012.

RODRÍGUEZ L, RODRIGUEZ P, GÓMEZ B, AYALA JC, OKSENBERG D, PEREZ-CASTILLA A, NETTO MG, SOFFER E, CROWELL MD: Long-term results of electrical stimulation of the lower esophageal sphincter for the treatment of gastroesophageal reflux disease. Endoscopy 45: 595-604, $2013 \mathrm{a}$.

RODRÍGUEZ L, RODRIGUEZ P, GÓMEZ B, AYALA JC, OKSENBERG D, PEREZ-CASTILLA A, NETTO MG, SOFFER E, CROWELL MD: Electrical stimulation therapy of the lower esophageal sphincter is successful in treating GERD: final results of open-label prospective trial. Surg Endosc 27: 1083-1092, 2013 b.

SALLAM HS, CHEN JD: Colonic electrical stimulation: potential use for treatment of delayed colonic transit. Colorectal Dis 15: e244-e249, 2013.

SANMIGUEL CP, HAGIIKE M, MINTCHEV MP, CRUZ RD, PHILLIPS EH, CUNNEEN SA, CONKLIN JL, SOFFER EE: Effect of electrical stimulation of the LES on LES pressure in a canine model. Am J Physiol Gastrointest Liver Physiol 295: G389-G394, 2008.

SONG GQ, CHEN JD: Gastric electrical stimulation on gastric motility in dogs. Neuromodulation 14: $271-277,2011$.

XU X, ZHU H, CHEN JD: Pyloric electrical stimulation reduces food intake by inhibiting gastric motility in dogs. Gastroenterology 128: 43-50, 2005.

YANG M, FANG DC, LI QW, SUN NX, LONG QL, SUI JF, GAN L: Effects of gastric pacing on gastric emptying and plasma motilin. World J Gastroenterol 10: 419-423, 2004.

YAO S, KE M, WANG Z, XU D, ZHANG Y, CHEN JD: Retrograde gastric pacing reduces food intake and delays gastric emptying in humans: a potential therapy for obesity? Dig Dis Sci 50: 1569-1575, 2005.

YIN J, CHEN J: Excitatory effects of synchronized intestinal electrical stimulation on small intestinal motility in dogs. Am J Physiol Gastrointest Liver Physiol 293: G1190-G1195, 2007. 